\title{
New species of karst-dwelling Pselaphinae from southwestern China (Coleoptera: Staphylinidae)
}

\author{
Zi-Wei YIN \\ Laboratory of Systematic Entomology, College of Life Sciences, Shanghai Normal University, 100 Guilin Road, Shanghai, 200234, China; \\ e-mail: pselaphinae@gmail.com
}

\author{
Accepted: \\ $10^{\text {th }}$ February 2020 \\ Published online: \\ $11^{\text {th }}$ March 2020
}

\begin{abstract}
Three cavernicolous species of the ant-loving beetle subfamily Pselaphinae are described based on the material collected in the dark zone of limestone caves in southwestern China. Batraxis liyunchuni sp. nov. and Nipponobythus alienoceps sp. nov. from Guizhou are the first and third cave-dwelling species of their respective genus, but they do not exhibit particular troglomorphy compared to epigean congeners. Zopherobatrus lusciosus sp. nov. from Chongqing, showing typical morphological adaptation to hypogeal lifestyle, is the second known representative of this obligate cavernicolous genus. In light of the discovery of a second species, the generic diagnosis of Zopherobatrus is modified accordingly.
\end{abstract}

Key words. Coleoptera, Staphylinidae, Goniaceritae, Batrisitae, new species, cave, Guizhou, Chongqing, China

Zoobank: http://zoobank.org/urn:lsid:zoobank.org:pub:8E4127DB-9AFC-4902-B411-4B43329B9A18

(C) 2020 The Authors. This work is licensed under the Creative Commons Attribution-NonCommercial-NoDerivs 3.0 Licence.

\section{Introduction}

The cave fauna of the diverse rove beetle subfamily Pselaphinae from the vast karst area in China and adjacent countries has drawn increasing attention from staphylinidologists (YIN \& JANTARIT 2019). Since NomURA \& WANG (1991) described the first species from Guilin, Guangxi, the Chinese fauna has been raised to 18 species in three genera (YIN \& Li 2015; YIN et al. 2010, 2011a, 2011b, 2015, 2016; Yin \& Zhоu 2018). Nevertheless, in comparison to other relatively well-studied arthropod groups with a rich cave fauna (e.g., over 140 species in 49 genera within the tribe Trechini (Carabidae) (TIAn et al. 2019) and approximately 150 cave-dwelling species of millipedes (Diplopoda) (LIU \& WynNe 2019)), the known species of cavernicolous Pselaphinae probably represents a small fraction of the total diversity, as only few of the karst areas in China have been properly sampled (DEHARVENG \& BEDOs 2000).

Recently Dr. Yun-Chun Li, a specialist on cave pseudoscorpions, sent me a series of unidentified pselaphine beetles collected in four limestone caves in the karst area of southwestern China. An identification of this material revealed three new species belonging to the tribes Brachyglutini, Iniocyphini, and Batrisini, which are described in this paper.

\section{Material and methods}

The type material of the new species described in this paper is housed in the Insect Collection of Shanghai Normal University (SNUC). The text of the specimen label is quoted verbatim in quotation marks ("), sub-provincial localities in Chinese are placed in parentheses.

Dissected parts were preserved in Euparal on plastic slides that were placed on the same pin with the specimens. The habitus images were taken using a Canon 5D Mark III camera in conjunction with a Canon MP-E $65 \mathrm{~mm} \mathrm{f} / 2.81-5 \mathrm{X}$ Macro Lens, and a Canon MT-24EX Macro Twin Lite Flash was used as the light source. Images of the morphological details were produced using a Canon G9 camera mounted to an Olympus CX31 microscope under reflected or transmitted light. Zerene Stacker (version 1.04) was used for image stacking. The line drawing of the aedeagi were produced using Adobe Illustrator CC 2018. All images were modified and grouped into plates using Adobe Photoshop CC 2018. 


\section{Taxonomy}

Supertribe Goniaceritae

Tribe Brachyglutini

\section{Genus Batraxis Reitter, 1881}

This is a diverse group comprising 65 species distributed mainly in the Oriental-Australian Region, with a few species reaching the eastern and southern Palaearctic Realm, and one (i.e., B. hampei Reitter, 1881, type species of the genus) occurring in Greece (WANG et al. 2016; WANG \& YIN 2016a, b; LÖBL 2017). Members have been commonly encountered in sifted samples of leaf litter or associated with decomposing logs, while two species from Japan were postulated to be inquilines of Lasius Fabricius, 1804 ants (Nomura 1986, Maruyama 2004). Here the first cavernicolous species of Batraxis is described.

\section{Batraxis liyunchuni sp. nov.} (Fig. 1)

Type material. Holotype: $\partial$, 'CHINA: SW China: Guizhou, Luodian County (罗甸县), Ban'geng Town (板庚乡), Ban'geng Village (板庚 村), Guanyin Cave (观音洞), N2531'6.84", E106³8'54.68", ca. 540 m, 8.x.2019, Yun-Chun Li leg.' (SNUC). Paratype: CHINA: 1 \%, same label data as holotype (SNUC).

Diagnosis. Body length approximately $2.0 \mathrm{~mm}$; with long, sparse pubescence; frons broad, with complete subantennal transverse sulcus; vertexal foveae distinct; male antennomere 10 protuberant at anteromesal corner, antennomere 11 with wide impressed area on mesal surface; median gular carina broad and elevated, with two small gular foveae close to each other; metaventrite with paired elongate lateral carinae in male; legs elongate and simple in both sexes; tergite IV with broad basal sulcus which is densely setose at middle, long discal carinae widely separated and sub-paralleled; aedeagus symmetrical, with relatively stout median lobe, parameres distinctly exceeding apex of median lobe.

Description. Male (Fig. 1A). Body reddish-brown, length from anterior margin of clypeus to apex of abdomen 2.02 $\mathrm{mm}$. Head rectangular, length from anterior margin of clypeus to head base $0.44 \mathrm{~mm}$, equals to maximum width across eyes; vertex finely punctate, sparsely pubescent, moderately convex, with pair of small vertexal foveae; antennal tubercles raised; frons flattened posteriorly and raised anteriorly at middle, merging with antennal tubercles to form transverse bridge; subantennal transverse sulcus complete; lacking vertexal sulcus connecting foveae; each eye composed of about 25 facets; antennae relatively elongate, length $0.95 \mathrm{~mm}$, with distinct club (Fig. 1B) formed by apical two antennomeres; antennomere 1 large, approximately 1.5 times as wide as 2 , antennomere 2 cylindrical, antennomeres 3 and 4 successively shorter,
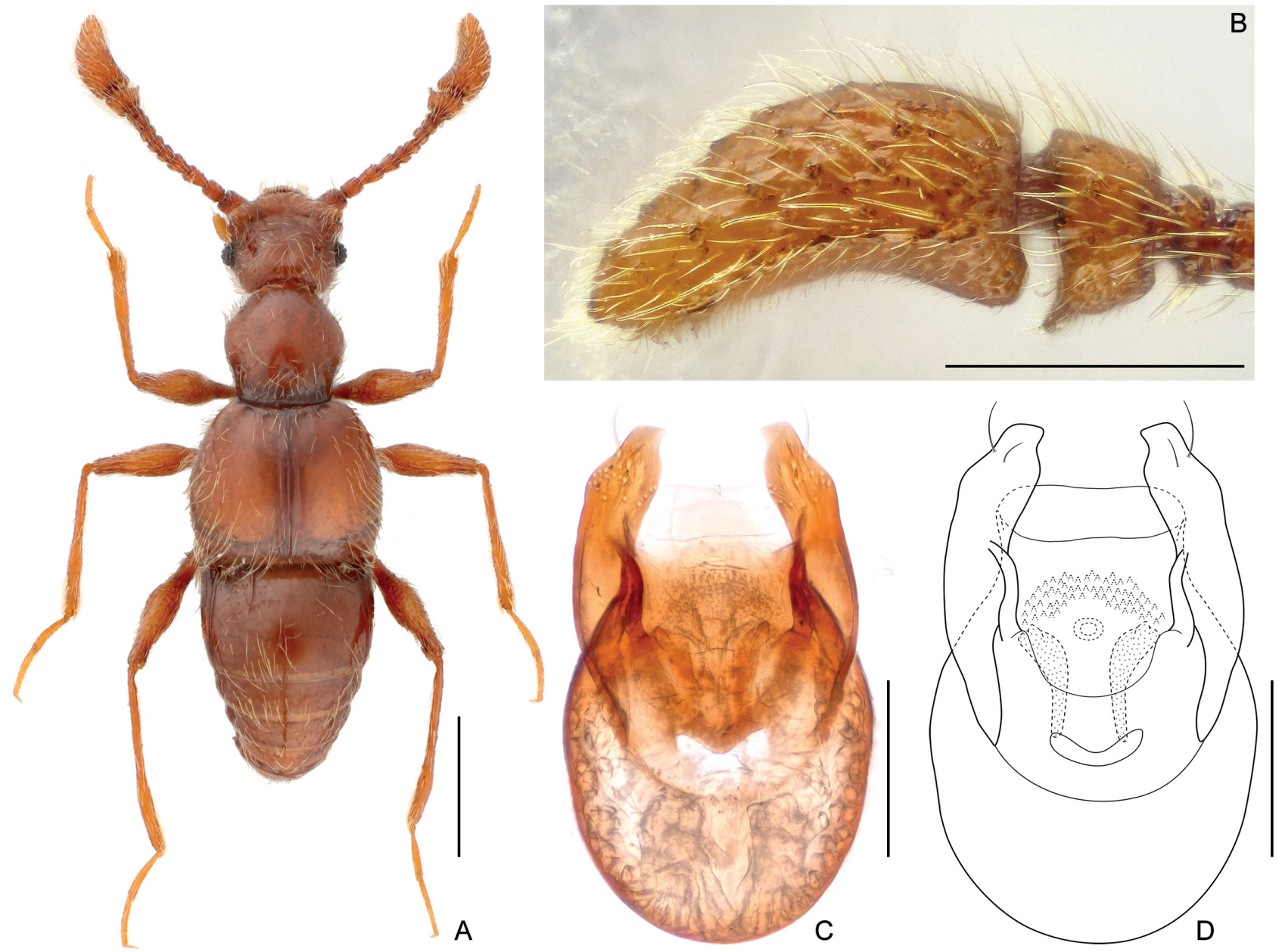

Fig. 1. Batraxis liyunchuni sp. nov., male. A - habitus; B - antennal club; C, D - aedeagus, ventral. Scale bars: 0.5 mm in A; 0.2 mm in B-D. 
narrowed at bases and broadening apically, antennomeres 5-9 short and transverse, antennomere 10 approximately twice as wide as antennomere 9, asymmetrical, with its anteromesal corner distinctly protuberant, antennomere 11 largest, curved mesally, with its mesal surface broadly impressed; median gular carina broad and elevated, with two small nude gular foveae close to each other. Pronotum almost glabrous, with sparse pubescence similar to those of head; length along midline $0.43 \mathrm{~mm}$, maximum width $0.44 \mathrm{~mm}$; with nude median and lateral antebasal foveae. Elytra wider than long, length along suture 0.69 $\mathrm{mm}$, maximum width $0.53 \mathrm{~mm}$, dorsal surface with sparse, long setae; each elytron with two punctiform basal foveae in shallow impressions; sutural stria complete, lacking discal longitudinal sulcus. Legs simple, without protuberances. Abdomen longer than wide, length along midline $0.73 \mathrm{~mm}$, maximum width $0.62 \mathrm{~mm}$; slightly constricted near base; tergite IV (first visible tergite) with broad basal impression, densely setose at middle; discal carinae long, widely separated, almost parallel to each other, about 0.4 times of total tergal length; marginal carinae complete and oblique. Length of aedeagus (Fig. 1C, 1D) $0.29 \mathrm{~mm}$ (including parameres), median lobe relatively stout, with large, oval diaphragm, parameres distinctly exceeding apex of median lobe, each broadened preapically, narrowed at apex, and with two preapical setae; endophallus comprises two elongate sclerites at middle, and numerous weakly sclerotized spine-like structures anteriorly.

Female. Similar to male in general appearance; antennomere 10 lacking protuberance, antennomere 11 similarly asymmetrical as male, but mesal surface lacking impression; metaventrite lacking lateral carinae; each eye composed of about 12 facets. Measurements (as for male): body length $2.0 \mathrm{~mm}$; length of head $0.44 \mathrm{~mm}$, equals to width; length of pronotum $0.44 \mathrm{~mm}$; maximum width $0.43 \mathrm{~mm}$; length of elytra $0.50 \mathrm{~mm}$, maximum width $0.67 \mathrm{~mm}$; length of abdomen $0.62 \mathrm{~mm}$, maximum width $0.54 \mathrm{~mm}$.

Comparative notes. This is a very distinct species which can be easily separated from all congeners from East Asia by the unique form of the sexually modified antennal club and laterally carinate metaventrite of the male, the simple legs of both sexes (the males of most Batraxis species have modified tibiae or protuberant protrochanters), and the form of the aedeagus.

Etymology. The new species is named after Yun-Chun $\mathrm{Li}$, who collected the type material of the new species.

Distribution. Southwestern China: Guizhou.

Comments. This is the first Batraxis species known to inhabit a cave environment. Both specimens were found walking on the ground in the dark zone of the cave (Y.C. Li, pers. comm.). However, B. liyunchuni sp. nov. exhibits no particular morphological adaptations (e.g., distinctly elongate appendages, reduction of eyes) as usually found in other obligate troglobitic pselaphines (e.g., Zopherobatrus Yin \& Li, 2015). With this regard, further field work both in and outside the cave is needed to determinate the biology of this species.

\section{Tribe Iniocyphini}

\section{Genus Nipponobythus Jeannel, 1958}

After a revision of the genus (LöBL 1965) 12 species were known, seven from China and five from Japan. Later Nomura \& LeE $(1992,1993)$ added two more species from South Korea. At present Nipponobythus is formally placed in the tribe Iniocyphini. Based on the shared presence of a smooth depression on the gena, KuRBATOv et al. (2007: 592) implicitly suggested a close relationship of the group, together with a number of related genera, to the tribe Proterini. Members are usually collected from leaf litter samples, and two Japanese species have been known to inhabit caves.

\section{Nipponobythus alienoceps sp. nov. (Fig. 2)}

Type material. Holotype: ' 'CHINA: SW China: Guizhou, Pingtang County (平塘县), Wanzi Village (湾子村), Ba-mao-chong (巴毛冲),

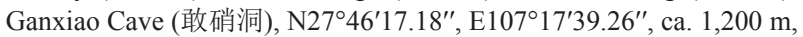
6.x.2019, Yun-Chun Li leg.' (SNUC). Paratypes: CHINA: 3 $\circ$, same label data as holotype (SNUC).

Diagnosis. Body length 1.65-1.81 mm; with dense, moderately long pubescence on head, pronotum, and elytra; male with strongly modified vertex and frons comprising complicated structures, vertex laterally with large setose area; female with head unmodified, frons roughly punctate instead; aedeagus symmetrical, apices of parameres pointed, endophallus mainly composed of weakly to strongly sclerotized spine-like structures.

Description. Male (Fig. 2A). Body reddish-brown, length (from anterior margin of clypeus to apex of abdomen) 1.65 mm. Head (Fig. 2B) sub-rectangular and strongly transverse, length from anterior margin of clypeus to head base 0.35 $\mathrm{mm}$, maximum width across eyes $0.43 \mathrm{~mm}$; vertex finely punctate, densely pubescent, strongly concave at middle, with pair of markedly raised projections each densely setose apically, anterior area deeply and transversely sulcate, lateral portions covered by dense, short setae; antennal tubercles only faintly raised; frons abruptly elevated at middle, forming vertical plane with clypeus; each eye composed of about 45 facets; antennae relatively elongate, length $0.68 \mathrm{~mm}$, with distinct club formed by apical three antennomeres; antennomere 1 and 2 distinctly larger than antennomeres 3-8, antennomere 3 elongate, antennomeres 4-8 each moniliform, antennomere 9 approximately twice size of 8 , subconical, antennomere 10 subconical and strongly transverse, antennomere 11 largest, broadest near middle and narrowing apically. Pronotum with moderately dense pubescence; slightly wider than long, length along midline $0.33 \mathrm{~mm}$, maximum width $0.37 \mathrm{~mm}$; with complete transverse antebasal sulcus connecting foveae, with nine short longitudinal ridges at base. Elytra much wider than long, length along suture $0.51 \mathrm{~mm}$, maximum width 0.69 $\mathrm{mm}$, dorsal surface with dense, long setae; each elytron with two nude foveae; sutural sulcus complete, lacking discal longitudinal sulcus. Legs simple, without protuberances. Abdomen wider than long, length along midline $0.64 \mathrm{~mm}$, maximum width $0.42 \mathrm{~mm}$; tergite IV (first visible 
tergite) with short discal carinae widely separated; both inner and outer marginal carinae complete and parallel; tergite VIII (Fig. 2C) strongly transverse, with two lateral and one middle projection along anterior margin; sternite IX (Fig. 2D) composed of two weakly-sclerotized, elongate plates. Length of aedeagus (Figs 2E, 2F) $0.24 \mathrm{~mm}$ (including parameres), median lobe and parameres symmetrical; each paramere roundly transverse and with pointed apex on posterior margin; endophallus with numerous weakly-sclerotized spine-like structure at middle portion, and with more elongate and more strongly sclerotized spines, and one elongate sclerite at basal portion.

Female. Similar to male in general appearance; head lacking modification, anterior portion of frons roughly punctate; each eye composed of about 8 facets. Measurements (as for male): body length 1.77-1.81 mm; length of head $0.34-0.37 \mathrm{~mm}$, width $0.37-0.41 \mathrm{~mm}$; length of antennae $0.67-0.70 \mathrm{~mm}$; length of pronotum $0.32-0.33 \mathrm{~mm}$; width $0.34-0.35 \mathrm{~mm}$; length of elytra $0.45 \mathrm{~mm}$, width $0.65-0.67$ $\mathrm{mm}$; length of abdomen $0.64 \mathrm{~mm}$, width $0.43-0.48 \mathrm{~mm}$.

Comparative notes. This is a very distinct species which can be easily separated from all congeners by the unique form of the sexually modified head of the male, and the configuration of the aedeagus.

Etymology. The new specific epithet alienoceps is an adjective combined from Latin 'aliēnus (exotic, foreign) and '-ceps (-headed)', referring to the strongly modified head of the male.

Distribution. Southwestern China: Guizhou.

Comments. Two Japanese species, i.e., N. latifrons Jeannel, 1958, and $N$. plagiatus Jeannel, 1958, have been reported to inhabit cave environments (JEANNEL 1958; TANOKUCHI 1985). In Guizhou all individuals of $N$. alienoceps sp. nov. were collected under a few decomposing sticks on wet ground in a completely dark environment deep within the cave (Y.-C. Li, pers. comm.).

\section{Supertribe Batrisitae \\ Tribe Batrisini}

\section{Genus Zopherobatrus Yin \& Li, 2015}

This monotypic genus is represented by a single eyeless species, Zopherobatrus tianmingyii Yin \& Li, 2015 from Guizhou, southwestern China (YIN \& Li 2015). The complete loss of compound eyes, coupled with the extremely elongate appendages, and its occurrence in the dark zone of the cave suggest $Z$. tianmingyii is an obligate troglobiont. Here, a second species with strongly reduced (but still present) eyes is described from Chongqing. In light of the discovery of a second species, the generic diagnosis of Zopherobatrus needs to be modified as follows.
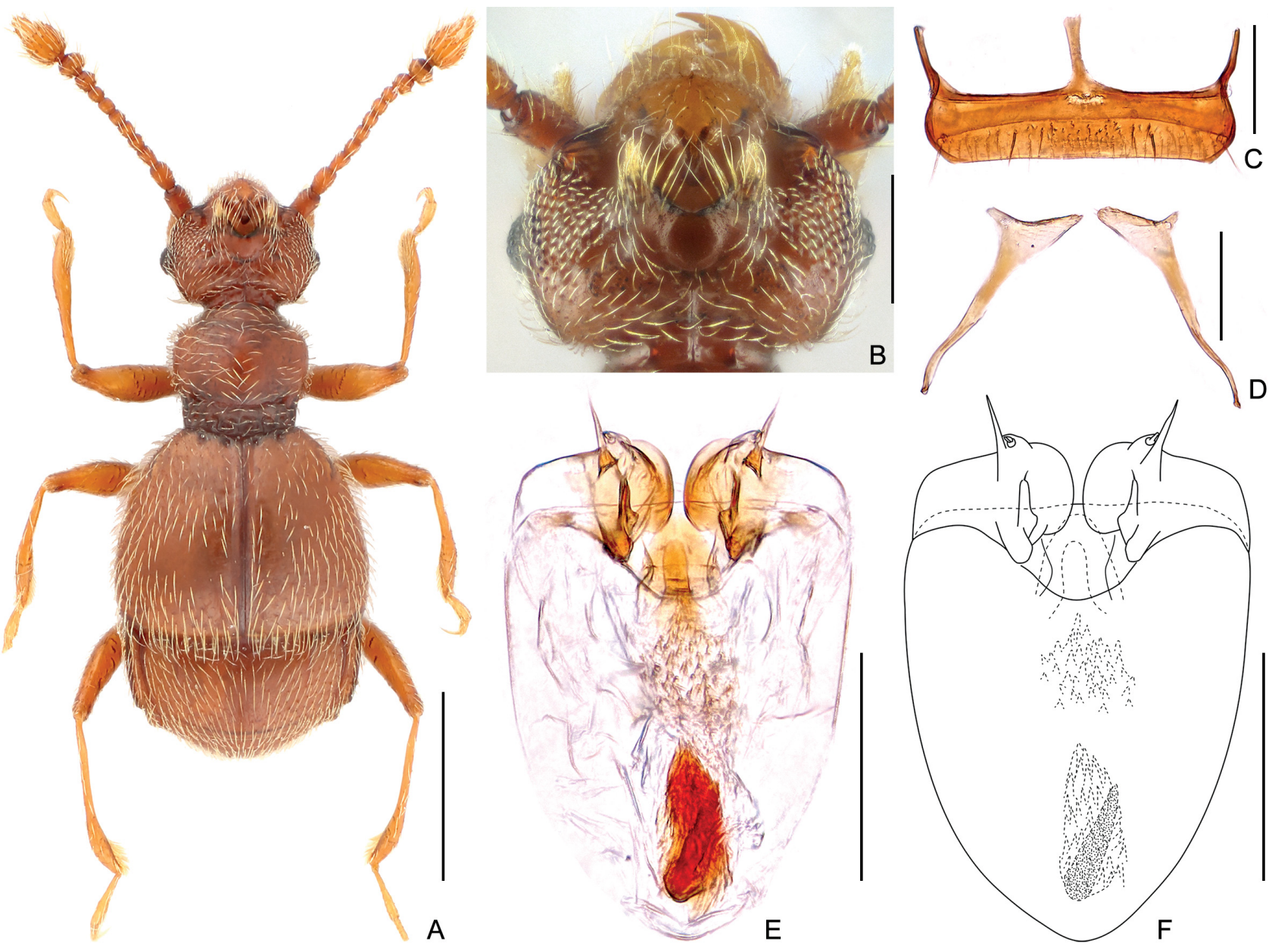

Fig. 2. Nipponobythus alienoceps sp. nov., male. A - habitus; B - head dorsum; C - tergite VIII; D - sternite IX; E-F - aedeagus, ventral. Scale bars: $0.5 \mathrm{~mm}$ in $\mathrm{A} ; 0.2 \mathrm{~mm}$ in $\mathrm{B}$; $0.1 \mathrm{~mm}$ in $\mathrm{C}-\mathrm{F}$. 
Revised diagnosis. General body form slender, with extremely elongate appendages. Head narrowed apically; median longitudinal carina on vertex faintly present; lacking frontal rostrum; with indistinct antennal tubercles; eyes strongly reduced to lacking. Pronotal disc moderately convex; median longitudinal sulcus present or absent, lateral longitudinal sulci usually present; lacking antebasal spines; lacking spines on lateral margins. Elytra strongly constricted at base, each elytron with two basal foveae; discal stria lacking to distinct; disc moderately to strongly convex. Tergite IV (first visible tergite) longest, with single marginal carina.

\section{Zopherobatrus lusciosus sp. nov. (Fig. 3)}

Type material. HoLоTYPE: $\hat{\partial}$, 'CHINA: SW China: Chongqing, Fengjie County (奉节县), Xinglong Town (兴隆镇), Da-ban-qiao Stockaded Village (大板桥寨), Taoyuan Village (桃源村), Zhangjiagou (张家 沟), Chuan Cave (穿洞子), N30 46'60", E109 28'10.2", ca. 905 m, 22.iii.2016, Yun-Chun Li leg.' (SNUC). ParatyPe: CHINA: 1 , same label data except ' $14^{\text {th }}$ Commune (14社), anonymous cave (无名洞), N30 50'42", E109³4'21", ca. 905 m' (SNUC).

Diagnosis. Body length 3.3-3.5 mm; vertex lacking sulcus connecting foveae, mediobasal ridge faintly present; eyes strongly reduced, with only a few ommatidia; pronotum lacking median longitudinal sulcus, with thin lateral longitudinal sulci; elytra moderately constricted at base, with distinct discal sulcus; mesotibia with long apical spine in male; tergite IV with sides nearly parallel, narrowed at middle; median lobe of aedeagus with ventral lobe at right side, dorsal lobe weakly sclerotized.

Description. Male (Fig. 3A). length from anterior margin of clypeus to apex of abdomen $3.46 \mathrm{~mm}$. Body reddish brown, antennae, mouthparts and tarsi lighter in color; most part of dorsal surface covered with long pubescence. Head (Fig. 3B) lengthily oval, length from anterior margin of clypeus to head base $0.76 \mathrm{~mm}$, maximum width across eyes $0.52 \mathrm{~mm}$; surface finely punctate; vertex slightly convex, foveae below level of posterior margins of eyes, lacking U-shaped sulcus connecting vertexal foveae, faint median carina extending from head base to anterior margin of eyes; eyes strongly reduced, indicated by three small ommatidia; postocular margins rather long, narrowing from eyes towards base; length of antennae $2.30 \mathrm{~mm}$, antennomeres each elongate; maxillary palpi with minute palpomere 1 and elongate palpomeres $2-4$; palpomere 4 lacking obvious thickened setae at anterolateral margins, with small apical palpal cone. Pronotum (Fig. 3C) wider than long, with round lateral margins, length along midline $0.62 \mathrm{~mm}$, maximum width $0.77 \mathrm{~mm}$, disc finely punctate;

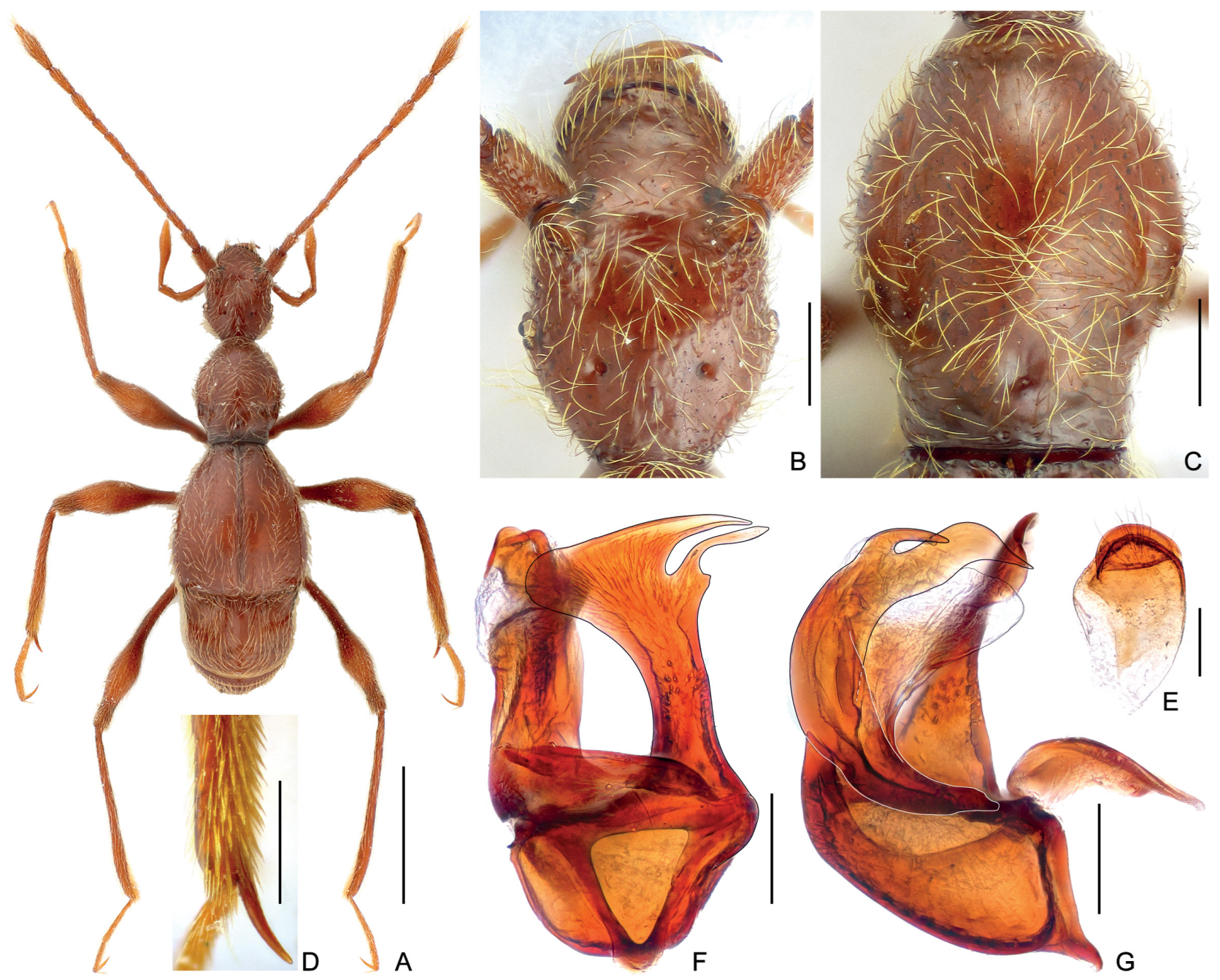

Fig. 3. Zopherobatrus lusciosus sp. nov., male. A - habitus; B - head dorsum; C - pronotum; D - apex of left mesotibia; E - sternite IX; F-G aedeagus, ventral (F) and lateral (G). Scale bars: $1.0 \mathrm{~mm}$ in A; $0.2 \mathrm{~mm}$ in B-E; $0.1 \mathrm{~mm}$ in F-G. 
lacking antebasal sulcus. Elytra approximately as long as wide, length along suture $1.08 \mathrm{~mm}$, maximum width 1.0 $\mathrm{mm}$; each elytron with two small basal foveae; disc finely punctate, covered with long setae. All legs elongate, mesotibiae (Fig. 3D) with long, slightly curved apical spine. Abdomen slightly longer than wide, length along midline $1.0 \mathrm{~mm}$, maximum width $0.85 \mathrm{~mm}$. Tergite IV (first visible tergite) longest, lacking modification; tergites V-VI combined much shorter than tergite IV; tergite VII as long as V and VI combined; tergite VIII semicircular. Sternite VIII semicircular, emarginate at middle of posterior margin. Aedeagus (Figs 3F-G) asymmetrical, length $0.42 \mathrm{~mm}$; basal capsule with triangular foramen; with moderately long basoventral projection; ventral lobe broadened at apical part, split to two major parts at apex; broad articulated dorsal lobe elongate, strongly sclerotized at base and weakly so apically; parameres fused to flattened, lamellate ventral membrane.

Female. Similar to male in general appearance; mesotibiae lacking apical spine; each eye composed of five ommatidia. Measurements (as for male): body length 3.38 $\mathrm{mm}$; length of head $0.79 \mathrm{~mm}$, width across $0.53 \mathrm{~mm}$; length of antennae $2.25 \mathrm{~mm}$; length of pronotum $0.63 \mathrm{~mm}$; maximum width $0.74 \mathrm{~mm}$; length of elytra $1.09 \mathrm{~mm}$, maximum width $1.0 \mathrm{~mm}$; length of abdomen $1.03 \mathrm{~mm}$, maximum width $0.87 \mathrm{~mm}$.

Comparative notes. The new species can be readily separated from Z. tianmingyii by the weakly developed vertexal sulcus and mediobasal ridge of the head, the presence of eyes in both sexes, the lack of median longitudinal sulcus of the pronotum, a relatively much border elytral base, a much more elongate apical spine of the male mesotibiae, and a totally different structure of the aedeagus.

Etymology. The Latin lusciosus $(-a,-u m)$ is an adjective meaning 'purblind, dim-sighted', referring to the strongly reduced eyes of the new species.

Distribution. Southwestern China: Chongqing.

Comments. Both individuals were found under a rock in relatively moist environments of the dark zones in the two caves (Y.-C. Li, pers. comm.).

\section{Acknowledgments}

Doctor Yun-Chun Li (China West Normal University, Nanchong, Sichuan) collected the specimens used in this paper, kindly donated them to SNUC, and shared biological information of the new species. Two anonymous reviewers critically read the draft manuscript and offered helpful comments. Financial support was provided by the National Natural Science Foundation of China (No. 31872965), and the Shanghai 'Phosphor' Science Foundation, China (19QA1406600).

\section{References}

DEHARVENG L. \& BEDOS A. 2000: The cave fauna of Southeast Asia: origin, evolution and ecology. Pp. 603-632. In: WILKENS
H., CULVER D. C. \& HUMPHREYS W. F. (eds): Ecosystems of the World 30: Subterranean Ecosystems. Elsevier, Amsterdam, 808 pp.

JEANNEL R. 1958: Révision des Psélaphides du Japon. Mémoires du Muséum National d'Histoire Naturelle (A: Zoologie) 18(1): 1-138.

LIU W. \& WYNNE J. J. 2019: Cave millipede diversity with the description of six new species from Guangxi, China. Subterranean Biology 30: 57-94.

LÖBL I. 1965: Beitrag zur Kenntnis der Gattung Nipponobythus Jeannel (Col. Pselaphidae). Annalen des Naturhistorischen Museums in Wien 68: 491-507.

LÖBL I. 2017: On the Batraxis species of Sri Lanka and the identity of Maya uzeli Blattný (Coleoptera: Staphylinidae: Pselaphinae). Folia Heyrovskyana, Series A 25(1): 13-19.

MARUYAMA M. \& SUGAYA H. 2004: A new myrmecophilous species of Batraxis (Coleoptera, Staphylinidae, Pselaphinae), associated with Lasius (Chthonolasius) sp. (Hymenoptera, Formicidae, Formicinae) from Hokkaido, Japan. Elytra 32(2): 321-325.

NOMURA S. 1986: Descriptions of two new myrmecophilous species

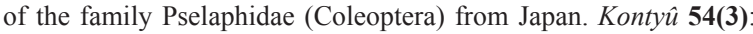
498-504.

NOMURA S. \& LEE C.-E. 1992: A revision of the family Pselaphidae (Coleoptera) from Chejudo Island, Korea. Esakia 32: 59-80.

NOMURA S. \& LEE C.-E. 1993: A revision of the family Pselaphidae (Coleoptera) from South Korea. Esakia 33: 1-48.

NOMURA S. \& WANG F.-X. 1991: Description of a new cavernicolous species of the genus Batrisodellus (Coleoptera, Pselaphidae) from southeast China. Elytra 19: 77-83.

TANOKUCHI Y. 1985: Notes on cavernicolous pselaphid beetles from Saruta-dô Cave, Southwest Japan. Journal of the Speleological Society of Japan 10: 8-13.

TIAN M., HUANG S., CHEN M. \& DING K. 2019: Remarkable cave-adapted ground beetles of the tribe Pterostichini from China: a new subgenus and three new species (Coleoptera: Carabidae). Annales de la Société Entomologique de France (N.S.) 55(1): 1-16.

WANG D., YIN Z.-W. \& WANG C.-X. 2016: On a collection of Batraxis Reitter (Coleoptera: Staphylinidae: Pselaphinae) from Hainan Island, southern China. Zootaxa 4109(1): 1-15.

WANG D. \& YIN Z.-W. 2016a: New species and records of Batraxis Reitter (Coleoptera: Staphylinidae: Pselaphinae) in continental China. Zootaxa 4147(4): 443-465.

WANG D. \& YIN Z.-W. 2016b: Supplement to the knowledge of the genus Batraxis Reitter (Coleoptera: Staphylinidae: Pselaphinae) of China. Zootaxa 4179(1): 111-114.

YIN Z.-W. \& JANTARIT S. 2019: Araneibatrus phuphaphet sp. nov., a new cavernicolous Pselaphinae from Satun Geopark, southern Thailand (Coleoptera: Staphylinidae: Pselaphinae). Zootaxa 4691 (1): 083-087

YIN Z.-W., JIANG, R.-X. \& STEINER H. 2016: Revision of the genus Araneibatrus (Coleoptera: Staphylinidae: Pselaphinae). Zootaxa 4097(4): 475-494.

YIN Z.-W. \& LI L.-Z. 2015: Zopherobatrus gen. n. (Coleoptera: Staphylinidae: Pselaphinae), a new troglobitic batrisine from southwestern China. Zootaxa 3985(2): 291-295.

YIN Z.-W., LI L.-Z. \& ZHAO M.-J. 2010: Araneibatrus gracilipes gen. et sp. n., a remarkable Batrisitae (Coleoptera, Staphylinidae, Pselaphinae) from P. R. China. ZooKeys 69: 53-58.

YIN Z.-W., LI L.-Z. \& ZHAO M.-J. 2011a: Discovery in the caves of Guangxi, China: three new troglobitic species of Tribasodites Jeannel (Coleoptera, Staphylinidae, Pselaphinae). Zootaxa 3065(1): 49-59.

YIN Z.-W., NOMURA S. \& LI L.-Z. 2015: Ten new species of cavernicolous Tribasodites from China and Thailand, and a list of East Asian cave-inhabiting Pselaphinae (Coleoptera, Staphylinidae). Acta Entomologica Musei Nationalis Pragae 55: 105-127.

YIN Z.-W., NOMURA S. \& ZHAO M.-J. 2011b: Taxonomic study on Batrisodellus Jeannel of China, with discussion on the systematic position of Batrisodellus callissimus Nomura \& Wang, 1991. Spixiana 34: 33-38. 